\title{
1 Non-genetic maternal effects shape individual differences in cortisol phenotypes in wild chimpanzees
}

Patrick J. Tkaczynski1,2,3*a, Fabrizio Mafessoni4,5a, Cédric Girard-Buttoz 1,2,3,6, Liran Samuni1,2,3,7,

$8{ }^{1}$ Department of Human Behavior, Ecology and Culture, Max Planck Institute for Evolutionary Anthropology,

9 Leipzig, Germany

$10{ }^{2}$ Department of Primatology, Max Planck Institute for Evolutionary Anthropology

$11{ }^{3}$ Taï Chimpanzee Project, Centre Suisse de Recherches Scientifiques, Abidjan, Côte d'Ivoire

$12{ }^{4}$ Department of Evolutionary Genetics, Max Planck Institute for Evolutionary Anthropology, Leipzig, Germany

135 Weitzmann Institute of Science, Department of Plant and Environmental Sciences, Rehovot, Israel

$14{ }^{6}$ The Great Ape Social Mind Lab, Institut des Sciences Cognitives, CNRS, Lyon, France

$157^{7}$ Department of Human Evolutionary Biology, Harvard University, Cambridge, MA, USA

$16{ }^{8}$ Universite de Neuchatel, Institut de Biologie, Cognition Compare, Neuchatel, Switzerland

179 Division of Psychology, University of Stirling, Stirling, UK

$18{ }^{10}$ Tropical Conservation Institute, Institute of Environment, College of Arts, Science and Education, Florida

19 International University, FL, USA

$20{ }^{11}$ Centre for Social Learning \& Cognitive Evolution, School of Psychology \& Neuroscience, University of St

21 Andrews, St Andrews, UK

2212 World Wide Fund for Nature, Dzanga Sangha Protected Areas, BP 1053, Bangui. Central African Republic

$23{ }^{13}$ Robert Koch Institute, Epidemiology of Highly Pathogenic Microorganisms, Berlin, Germany

$24{ }^{14}$ Unité de Formation et de Recherche Biosciences, Université Félix Houphouët Boigny, Abidjan, Côte d'Ivoire

$25 \quad 15$ WWF Deutschland, Berlin, Germany

2616 United Nations Environment Programme, Washington, DC, USA

2717 Interim Group Primatology, Max Planck Institute for Evolutionary Anthropology

2818 German Centre for Integrative Biodiversity Research, Leipzig, Germany

$29 *$ Corresponding authors: pjresearchltd@gmail.com; fabrizio.mafessoni@gmail.com

30 a These lead authors contributed equally to the study.

31 b These senior authors contributed equally to the study.

32 Keywords: heritability; stress; plasticity; glucocorticoids; selection; circadian rhythm 
34 Glucocorticoids, such as cortisol, mediate homeostatic processes, allowing individuals to

35 adjust to fluctuating environments. The regulation of circadian cortisol responses, a key

36 homeostatic function, has been shown to be heritable. However, to understand better the

37 role of parental care in shaping physiological functioning in long-lived mammals with

38 protracted parental care, there is a need to disentangle genetic and non-genetic parental

39 contributions to variation in glucocorticoid phenotypes. We used a dataset of 6,123 cortisol

40 measures from urine samples from 170 wild chimpanzees spanning 18 years of data

41 collection. We found consistent inter-individual differences in circadian cortisol

42 phenotypes, with differences most apparent when considering average cortisol levels given

43 the effect of time of day. Maternal effects explained around 10\% (2-18\%) variation in these

44 average cortisol levels, while variation attributable to genetic factors was not

45 distinguishable from zero. Our results indicate, relative to genetic effects, a qualitatively

46 stronger influence of mothers, whether via epigenetic processes or via behavioral priming

47 for coping with stressors, in shaping cortisol phenotypes in this species. This provides

48 novel insight into the vital role of mothers in the developmental plasticity of long-lived

49 mammals and, more generally, the selective pressures shaping physiological plasticity. 


\section{Introduction}

In vertebrates, glucocorticoids (GCs), secreted via the hypothalamic-pituitary-

56 adrenal (HPA) axis, facilitate homeostasis via mediation of metabolic, immune, and

57 behavioral responses to intrinsic and extrinsic stressors (Sapolsky et al., 2000; Selye, 1976;

58 Smith and Vale, 2006; Tsigos and Chrousos, 2002). As a consequence of this multi-faceted

59 and dynamic role, the regulation of HPA axis activation and GC secretion is of broad

60 interest to ecologists and evolutionary biologists seeking to understand how animals adapt

61 to changing environments (Beehner and Bergman, 2017; Bonier and Cox, 2020; Bonier and

62 Martin, 2016; Guindre-Parker, 2020, 2018; Guindre-Parker et al., 2019). Despite the

63 flexibility of HPA axis activity in response to external and internal stimuli, numerous

64 studies demonstrate consistent individual differences in HPA axis activity and reactivity to

65 environmental stimuli (Schoenemann and Bonier, 2018; Taff et al., 2018). Recent evidence

66 suggests that inter-individual variation in HPA axis regulation can be predictive of variation

67 in fitness outcomes (Bonier and Cox, 2020; Campos et al., 2021). For example, female

68 baboons with consistently elevated HPA axis activity live substantially shorter lives than

69 those with lower HPA axis activity (Campos et al., 2021). Given the profound fitness effects

70 of individual differences in HPA axis activity and regulation, understanding the relative role

71 of genetics, experience, and environment in shaping these GC phenotypes is key to

72 understanding the evolution of physiological plasticity (Bonier and Martin, 2016; Guindre-

73 Parker, 2018).

In many wild animal populations, environmental heterogeneity can increase within-

75 individual variation in average GC levels and mask between-individual differences (Baugh 
et al., 2014; Cook et al., 2012; Grace and Anderson, 2014; Montiglio et al., 2015; Sparkman

et al., 2014; Taff et al., 2018; Tkaczynski et al., 2019). As a consequence, more recent

78 studies have begun to focus on the degree in which individuals vary in GC secretion in

79 response to shifting environmental gradients, i.e. GC reaction norms (Araya-Ajoy et al.,

80 2015; Araya-Ajoy and Dingemanse, 2017; Guindre-Parker, 2020; Guindre-Parker et al.,

81 2019; Sonnweber et al., 2018). In humans, the circadian cortisol (the main GC in

82 vertebrates) pattern is a well described reaction norm: levels rise gradually during sleep

83 prior to a peak upon awakening, followed by declines throughout the day (Weitzman et al.,

84 1971). A wealth of human studies reveal that deviations from this pattern, typically caused

85 by a lack of a decline in cortisol levels during the latter half of the day, are related to poor

86 physical and/or mental health (Butler et al., 2017; Carrion et al., 2002; Corbett et al., 2006;

87 Gonzalez et al., 2009; Gustafsson et al., 2010; Saridjan et al., 2010; Sephton et al., 2000;

88 Zilioli et al., 2016), and may also be predictive of survival (Sephton et al., 2000). Results

89 from human twin studies indicate as much as $60 \%$ of the variation in circadian cortisol

90 reactivity may be explained by genetic effects (Bartels et al., 2003a, 2003b; Gustafsson et

91 al., 2011; Steptoe et al., 2009). While twin studies in humans have been important in

92 revealing the genetic regulation of circadian cortisol responses, these studies are

93 constrained in their ability to disentangle the genetic and non-genetic parental effects

94 shaping this GC phenotype (Morris et al., 2020).

Circadian cortisol responses have recently begun to receive attention within non-

96 human animal ecology (Behringer et al., 2020; Emery Thompson et al., 2020; Girard-Buttoz

97 et al., 2021; Sonnweber et al., 2018). Species with protracted development phases and

98 prolonged parental dependencies offer exciting opportunities to better quantify the 
99 relative influence of genetic or non-parental effects on circadian cortisol regulation. These

100 insights can help us understand whether protracted development as a life history

101 adaptation has led to, and potentially been selected for, a greater influence of parental

102 effects on offspring physiology.

104 drivers of trait variation (Moore et al., 2019). In experimental rodent studies, maternal

105 cortisol levels during pregnancy and during post-partum offspring rearing, as well as rates

106 of maternal interaction with offspring, are all predictors of offspring cortisol levels and

107 reactivity (Champagne and Curley, 2009; Maccari et al., 2014). Rodent studies also suggest

108 that maternal effects may occur via epigenetic processes, such as DNA methylation of GC

109 receptor promotor regions, leading to altered responsivity to stressors (Champagne, 2008;

110 Champagne and Curley, 2009; Zhang et al., 2013). Non-human primate (hereafter primate)

111 studies of the role of maternal effects on cortisol secretion and reactivity have typically

112 employed maternal deprivation paradigms, either via experimental separations or due to

113 naturally occurring maternal loss (Champagne and Curley, 2009; Girard-Buttoz et al., 2020;

114 Rosenbaum et al., 2020). Here, maternal loss is linked to elevations in cortisol levels or

115 alterations to diurnal rhythm (Girard-Buttoz et al., 2020; Shannon et al., 1998), however,

116 these effects do not necessarily last into adulthood (Girard-Buttoz et al., 2020; Rosenbaum

117 et al., 2020). Similarly, in human studies, tests of maternal effects on cortisol regulation

118 classically examine the consequences of negative maternal or early life circumstances (e.g.

119 poor mental or physical health, low socioeconomic status, or maternal loss (reviewed in

120 Champagne and Curley, 2009). Here, maternal loss or early life adversity related to

121 maternal condition are associated with elevated HPA activity in offspring, which can last 
122 into adulthood for some individuals. Therefore, much of what we know about maternal,

123 rather than genetic, effects on cortisol regulation in long-lived mammals is derived from

124 studies of manipulated and/or extreme maternal circumstances.

In our study, we tackle the challenge of disentangling the relative contributions of

126 genetic and non-genetic maternal effects to variation in cortisol phenotypes in wild

127 chimpanzees. Like humans, chimpanzees are long-lived mammals with protracted

128 developmental phases (Bründl et al., 2021; Crockford et al., 2020; Nakamura et al., 2014;

129 Samuni et al., 2020; Stanton et al., 2020). In addition, many of the environmental factors

130 influencing variation in cortisol levels in chimpanzees are established (Emery Thompson et

131 al., 2020, 2010; Muller and Wrangham, 2004; Preis et al., 2019; Samuni et al., 2019;

132 Sonnweber et al., 2018; Wessling et al., 2018a, 2018b), and, therefore, can be accounted

133 and controlled for when modeling individual variation in cortisol phenotypes.

First, we examine whether there are consistent individual differences in circadian

135 cortisol responses in five different communities and two subspecies of wild chimpanzees

136 (western, Pan troglodytes verus and eastern, Pan troglodytes schweinfurthii). The dataset

137 includes 170 individuals representing adults and immature individuals of both sexes. Using

138 Bayesian analyses and permutation tests within the framework of an animal model

139 approach (Wilson et al., 2010), we present estimates of the relative contributions of

140 genetic, maternal, and environmental effects to circadian cortisol responses in this wild,

141 long-lived mammal.

142 In chimpanzees, as in humans, cortisol secretion peaks with the awakening

143 response, followed by a decline throughout the day (Muller and Lipson, 2003). Consistent 
144 individual differences in circadian cortisol responses are discernible in adult males

145 (Sonnweber et al., 2018), and in both sexes, these patterns vary due to aging (Emery

146 Thompson et al., 2020) during ill health (Behringer et al., 2020), or following traumatic

147 events such as maternal loss during immaturity (Girard-Buttoz et al., 2021). Chimpanzees

148 are a relatively long-lived species, have a gestation period of approximately 8 months, and

149 a prolonged immature dependency lasting at least 10 years, in which there is emerging

150 evidence of maternal influences in growth, survival, and future reproductive success

151 (Crockford et al., 2020; Nakamura et al., 2014; Samuni et al., 2020; Stanton et al., 2020).

152 Therefore, during both pre- and post-natal phases, there is a long period in which maternal

153 and environmental factors can shape endocrine phenotypes that endure throughout

154 adulthood in chimpanzees. Interestingly, a recent cross taxa meta-analysis found a

155 generally stronger influence of maternal effects on trait variation in general in species

156 without parental care compared to those with parental care (Moore et al., 2019). This meta-

157 analysis included a number of studies on non-human primates and other mammal species

158 in which postnatal care is present. However, none of these species has the extended period

159 of immature dependency on mothers that is observed in human and non-human apes.

160 Therefore, we anticipated both genetic and non-genetic maternal effects to strongly

161 contribute to variation in this phenotype in chimpanzees.

\section{Results}

164 We used long-term behavioral, demographic, and physiological data collected

165 between 2000 and 2018 from two field sites of two sub-species of chimpanzee. In Taï 
166 National Park $\left(5^{\circ} 52^{\prime} \mathrm{N}, 7^{\circ} 20^{\prime} \mathrm{E}\right)$, Côte d'Ivoire, data were collected from three communities

167 of western chimpanzees (East, North, and South; Wittig and Boesch, 2019) and in Budongo

168 Conservation Field Station, Uganda $\left(2^{\circ} 03^{\prime} \mathrm{N}, 31^{\circ} 46^{\prime} \mathrm{E}\right)$, data were collected from two

169 communities of eastern chimpanzees (Sonso and Waibira; Reynolds, 2005; Samuni et al., 170 2014).

$171 \quad$ Urine and fecal samples were collected from individuals of all ages (2-53 years old)

172 within these communities. For each urine sample ( $n=6,123$ samples), we quantified cortisol

173 levels using liquid chromatography-tandem mass spectrometry (LCMS; Hauser et al., 2008)

174 and corrected for variation in water content in the urine using the specific gravity (SG) of

175 each sample (Miller et al., 2004). Therefore, we report urinary cortisol levels as ng

176 cortisol/ml SG. From the fecal samples, we genotyped DNA extracts using a two-step

177 amplification method including 19 microsatellite loci (per Arandjelovic et al., (2009).

178 In combination with behavioral observations of mother-offspring dyads, these

179 genotypes allowed us to generate a pedigree containing 159 named mothers and 50 named

180 fathers; 310 offspring had known mothers and 185 offspring had both known mothers and

181 fathers). Following stringent criteria to measure circadian cortisol responses (see below),

182 we included 170 individuals from this pedigree in our final dataset. Table 1 describes

183 sampling by pedigree and group. Figure S1 in the Supplementary Materials illustrates the

184 pedigree for individuals with urinary cortisol values in our study. 
187 Table 1: Summary statistics for final dataset used in the study. In total, 6,123 urinary cortisol values

188 from 170 individuals were included in the study. Note that certain individuals fall into several pedigree

189 categories (e.g. an individual can be a father and have a maternal or paternal sibling), therefore, the

190 number of individuals in pedigree categorization exceeds 170. The range of numbers of years of

191 sampling of individuals in the dataset was $1-13$ years, with a mean \pm SD of $2.63 \pm 3.01$ years.

\begin{tabular}{|c|c|c|c|}
\hline & $\begin{array}{r}\mathrm{N} \\
\text { individuals }\end{array}$ & $\begin{array}{r}\mathrm{N} \\
\text { samples }\end{array}$ & $\begin{array}{r}\text { Mean }( \pm \mathrm{SD}) \mathrm{N} \text { of } \\
\text { samples per } \\
\text { subject }\end{array}$ \\
\hline All & 170 & 6,123 & $36.02( \pm 48.17)$ \\
\hline Adult males & 48 & 3,243 & $67.56( \pm 79.97)$ \\
\hline Adult females & 69 & 1,742 & $23.86( \pm 19.72)$ \\
\hline Immature males & 37 & 545 & $17.03( \pm 16.58)$ \\
\hline Immature females & 32 & 593 & $15.95( \pm 11.09)$ \\
\hline \multicolumn{4}{|l|}{ By pedigree } \\
\hline Mothers with offspring in dataset & 19 & 648 & $34.11( \pm 24.20)$ \\
\hline Fathers with offspring in dataset & 11 & 977 & $88.82( \pm 77.03)$ \\
\hline Individuals with only maternal half siblings in dataset & 18 & 924 & $51.33( \pm 58.59)$ \\
\hline Individuals with only paternal half siblings in dataset & 28 & 699 & $24.96( \pm 22.04)$ \\
\hline Individuals with full siblings in dataset & 2 & 135 & $67.50( \pm 7.78)$ \\
\hline $\begin{array}{l}\text { Individuals with both maternal \& paternal half } \\
\text { siblings in dataset }\end{array}$ & 31 & 1,467 & $47.32( \pm 58.23)$ \\
\hline Individuals without relations in dataset & 62 & 1,928 & $31.10( \pm 48.20)$ \\
\hline \multicolumn{4}{|l|}{ By Population-group } \\
\hline Taï-East & 33 & 1,531 & $46.39( \pm 72.61)$ \\
\hline Taï-North & 24 & 842 & $35.08( \pm 28.92)$ \\
\hline Taï-South & 51 & 2,470 & $48.43( \pm 56.58)$ \\
\hline Budongo-Sonso & 45 & 1,171 & $24.40( \pm 17.82)$ \\
\hline Budongo-Waibira & 17 & 109 & $7.79( \pm 3.34)$ \\
\hline
\end{tabular}




\section{Repeatability}

We used linear mixed-effect models (LMMs) with a Gaussian error structure to test

196 adjusted repeatability, i.e., the proportion of variance attributable to between-individual

197 differences given conditional effects (Dingemanse and Dochtermann, 2013; Nakagawa and

198 Schielzeth, 2010), of both urinary cortisol levels $\left(R^{2}\right)$ and cortisol reaction norms $\left(R N^{2}\right)$, i.e.

199 circadian cortisol responses. Our key predictor of cortisol level variation (log-transformed

200 to achieve a symmetrical distribution) was time of day, which we converted into a

201 continuous, hours-since-midnight value for each sample. Previous research found higher

$202 R N^{2}$ for the quadratic term of time of day in our study populations (Sonnweber et al., 2018);

203 therefore, we included time of day as both linear and quadratic terms to model the

204 potential circadian responses. We included as fixed effects variables previously shown to

205 influence urinary cortisol levels (see Materials \& Methods for full details): the age of the

206 individual at the day of sampling (in years); group size; the male-to-female sex-ratio; the

207 sine and cosine of date (to account for seasonality); LCMS methodology; and a categorical

208 variable delineating individuals based on demography and reproductive state (five levels:

209 "adult male", "lactating female”, “cycling female”, "immature male”, and "immature female";

210 see Methods for description of variables). For the random effects of all models, we created

211 a factor variable composed of group identity and the sampling year (termed "group-year"),

212 and a variable to account for samples being pooled from various research projects ("project

213 identity").

$214 \quad$ We fitted three models: (i) an intercept null model, which included the fixed and

215 random effects described above, (ii) a random intercept model, which added random 
216 intercepts for individual identity and a dummy variable composed of individual identity

217 and the sampling year (termed "ID-year"; used to compare within-year and between year

218 repeatability, see below), and (iii) a reaction norm model by including random slopes for

219 the linear and quadratic terms of time of day within the random effects of individual

220 identity and ID-year.

221 Using a model comparison approach and leave-one-out cross validation (Vehtari et al.,

$2222021,2019,2017)$, we found strong support for the inclusion of the random intercepts for

223 individual identity, but weak support for the inclusion of random slopes within these

224 effects (Table S1). This pattern was also reflected in the observed repeatability estimates

225 (Table 2). Using custom code adapted from a previous study (Sonnweber et al., 2018), from

226 the reaction norm model, we calculated a within-year $R^{2}$ estimate (variance explained by

227 the ID-year variable) of $0.09(95 \%$ confidence intervals $=0.06,0.13)$ and a between-years

$228 R^{2}$ estimate (individual identity variable variance) of 0.05 (95\% confidence intervals $=0.02$,

229 0.07). We found substantial support for consistent individual differences in circadian

230 reaction norm intercepts, i.e., average cortisol levels given the effect of time of day, with a

$231 R N^{2}$ estimate for the intercept of $0.47(95 \%$ confidence intervals $=0.30,0.67)$. Although the

232 mean $R N^{2}$ estimates for the linear and quadratic time of day slopes, 0.20 and 0.21

233 respectively, suggested a substantial proportion of variance in these phenotypes are

234 attributed to individual differences, these estimates were associated with a large amount of

235 uncertainty, with the lower credible intervals of both slopes close to 0.

236 The apparent lack of between individual differences in circadian slopes was

237 unexpected given the strong evidence for consistent individual differences in this 
238 phenotype in a previous study of adult male chimpanzees, a dataset which included

239 individuals in our present study (Sonnweber et al., 2018). Therefore, to examine if the

240 inclusion of adult females and immatures in our dataset contributed to uncertainty to our

$241 R N^{2}$ slope estimates, we ran repeatability analyses for each separate demographic (adult

242 males, adult females, immatures; see Supplementary Materials for model specifications).

243 For all demographics, we still observed a high amount of uncertainty for our $R N^{2}$ slope

244 estimates (Table 2). Generally, across and within demographics we found strong support

245 for consistent individual differences in reaction norm intercepts rather than slopes. The

$246 R N^{2}$ intercept estimates for adult males and females were clearly non-zero (Table 2); for

247 immatures, although the estimate was high $\left(R N^{2}=0.43\right)$, the CI range was very wide,

248 suggesting uncertainty.

249 Figure 1 illustrates the urinary cortisol circadian responses of four randomly selected

250 father-mother-offspring triads from four groups in our study (for the Waibira group, we

251 had insufficient numbers of individuals to represent such a triad). Figures S3-S5 in the

252 Supplementary Materials respectively illustrate the circadian cortisol responses for all

253 adult male, adult female, and immature subjects included in the study. Tables S2-S9 in the

254 Supplementary Materials provides the model summary for the fixed and random effects of

255 the reaction norm models of each demographic. 
Table 2: Repeatability coefficients from reaction norm models quantifying circadian cortisol responses

260 in wild chimpanzees. Repeatability coefficients were calculated across all individuals ( $n=170)$, then

261 within the specific demographics of adult males $(n=46)$, adult females $(n=69)$, and immatures $(n=69)$.

262 Note that certain individuals (n=14) appear both as adults and immatures in the overall dataset.

\begin{tabular}{|c|c|c|c|}
\hline Demographic & Coefficient & Estimate & (lCI, uCI) \\
\hline \multirow[t]{5}{*}{ All individuals combined } & Within-year $R^{2}$ & 0.09 & $0.06,0.13$ \\
\hline & Between years $R^{2}$ & 0.05 & $0.02,0.07$ \\
\hline & $R N^{2}$ intercept & 0.47 & $0.30,0.67$ \\
\hline & $R N^{2}$ linear slope & 0.20 & $0.00,0.86$ \\
\hline & $R N^{2}$ quadratic slope & 0.21 & $0.00,0.89$ \\
\hline \multirow[t]{5}{*}{ Adult males } & Within-year $R^{2}$ & 0.08 & $0.04,0.14$ \\
\hline & Between years $R^{2}$ & 0.04 & $0.00,0.08$ \\
\hline & $R N^{2}$ intercept & 0.44 & $0.13,0.77$ \\
\hline & $R N^{2}$ linear slope & 0.27 & $0.00,0.91$ \\
\hline & $R N^{2}$ quadratic slope & 0.25 & $0.00,0.93$ \\
\hline \multirow[t]{5}{*}{ Adult females } & Within-year $R^{2}$ & 0.06 & $0.00,0.13$ \\
\hline & Between years $R^{2}$ & 0.05 & $0.00,0.11$ \\
\hline & $R N^{2}$ intercept & 0.87 & $0.61,0.99$ \\
\hline & $R N^{2}$ linear slope & 0.47 & $0.00,0.99$ \\
\hline & $R N^{2}$ quadratic slope & 0.39 & $0.00,0.98$ \\
\hline \multirow[t]{5}{*}{ Immatures } & Within-year $R^{2}$ & 0.20 & $0.08,0.33$ \\
\hline & Between years $R^{2}$ & 0.08 & $0.00,0.18$ \\
\hline & $R N^{2}$ intercept & 0.43 & $0.00,0.79$ \\
\hline & $R N^{2}$ linear slope & 0.22 & $0.00,0.74$ \\
\hline & $R N^{2}$ quadratic slope & 0.19 & $0.00,0.69$ \\
\hline
\end{tabular}




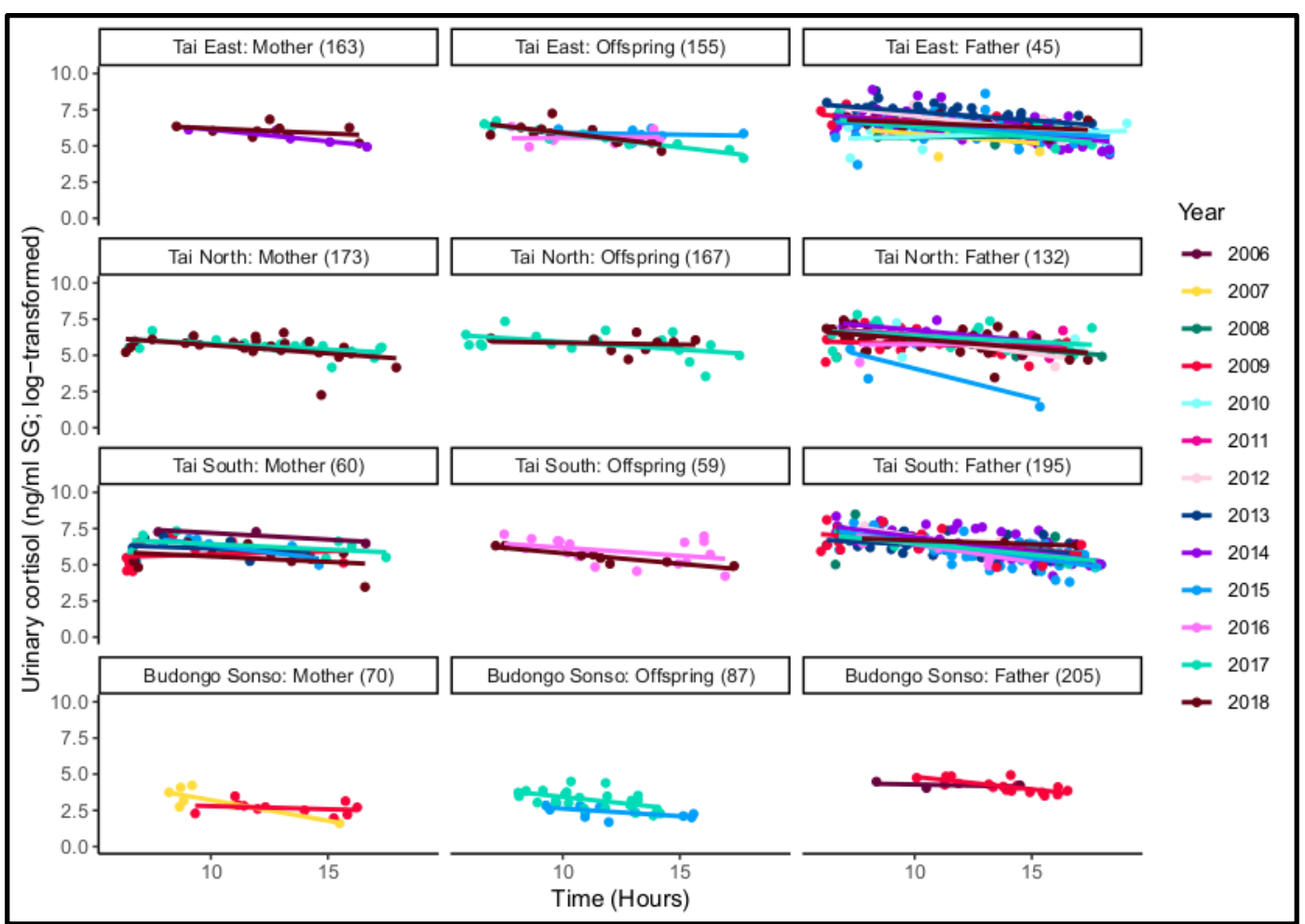

Figure 1: Circadian reaction norms for urinary cortisol levels ( $\mathrm{ng} / \mathrm{ml} \mathrm{SG}$; log transformed) for triads of

267 father-mother-offspring in four of our study communities (for the Budongo Waibira group, we had

268 insufficient numbers of individuals to represent such a triad). The points represent individual sample

269 values, the slopes individual responses to time of day; both sample values and responses are shaded

270 according to the year in which they were collected, respectively. The numbers in parentheses above

271 each panel indicate the identity of the individual as it appears in the pedigree (Figure S1). 
277 additive genetic variance in a trait. Our animal model was identical in structure to those

278 constructed for repeatability, with the major exception being the inclusion of the pedigree

279 as a random effect (Wilson et al., 2010). In addition, to partition the relative contribution of

280 maternal effects (the main caregiver), we also included the identity of the mother of the

281 individual sampled as a random effect.

We computed the genetic $\left(\mathrm{h}^{2}\right)$ and maternal $\left(\mathrm{m}^{2}\right)$ components of heritability as the

283 proportion of inter-individual variance explained by the pedigree and the maternal

284 identity, respectively. Specifically, we calculated $\mathrm{h}^{2}$ and $\mathrm{m}^{2}$ for the inter-individual variance

285 in the average cortisol levels ( $\mathrm{h}^{2}$ intercept and $\mathrm{m}^{2}$ intercept), and in cortisol responses to the linear

$286\left(\mathrm{~h}^{2}\right.$ linear and $\mathrm{m}^{2}$ linear $)$ and quadratic $\left(\mathrm{h}^{2}\right.$ quadratic and $\mathrm{m}^{2}$ quadratic $)$ terms for time of day. We also

287 estimated the proportion of covariance between intercept, linear slope, and quadratic

288 slopes explained by additive genetic or maternal factors (Wilson et al., 2010).

The relative contribution of our random effects to variation in circadian cortisol

290 responses in wild chimpanzees are shown in Figure 2, with a summary of the maternal and

291 genetic effects in Table 3 (full details of all variance components are in Table S10 and Table

292 S11 of the Supplementary Materials). Maternal effects explain about $10 \%$ of the variance of

293 the reaction norm intercept $\left(\mathrm{m}^{2}\right.$ intercept $\left.=0.10\right)$, with $90 \%$ credibility intervals (hereafter

$29490 \%$ CI, 0.02-018) higher than the point estimate for genetic effects, which is an order of

295 magnitude lower $\left(h^{2}\right.$ intercept $\left.=0.01\right)$. Specifically, we estimate that $93 \%$ of the probability

296 mass of $\mathrm{m}^{2}$ intercept is higher than the posterior probability of $\mathrm{m}^{2}$ intercept. For the linear and

297 quadratic circadian slope terms, the $90 \%$ CIs of the proportion of variance explained by

298 maternal effects are very wide $\left(\mathrm{m}^{2}\right.$ linear $=0.09 ; 0.000-0.51 ; \mathrm{m}^{2}$ quadratic $\left.=0.03 ; 0.00-0.27\right)$ and 
299 prevent a comparison with that explained by genetic effects $\left(\mathrm{h}^{2}\right.$ linear $=0.06 ; 0.00-0.42$;

$300 \quad h^{2}$ quadratic $\left.=0.04 ; 0.00-0.36\right)$. Similar estimates were obtained using independent models, in

301 which either group identity was used as predictor in place of continuous predictors such as

302 group size (Figure S6, Table S12), or in which only individuals sampled in the Taï forest

303 (4,843 samples belonging to 111 individuals) were used, excluding the possibility that

304 artifacts due to unaccounted population structure are present (Figure S7, TableS13).

306 Table 3). In addition, their values are by definition bound to be positive as they are derived

307 from the variance components of the random effects in the animal model. Hence, to assess

308 whether maternal and genetic factors determine detectable non-zero effects and to test

309 whether the differences between $\mathrm{m}^{2}$ and $\mathrm{h}^{2}$ could be due to chance, we performed re-

310 sampling of the data and calculated the proportion of cases in which estimates were higher

311 than for the observed data (i.e., false positives). Specifically, we reshuffled the identities of

312 the individuals within their communities (and thus maintaining control of group-level

313 environmental and social factors) 100 times in the additive genetic matrix. Individuals

314 newly classified as siblings after the permutation of the genetic matrix, were assigned to

315 the same mother in the predictor "maternal identity", so that genetic relationships and

316 maternal effects were always concordant. By doing this, we obtained permutations of the

317 data that simulated genetic and maternal relationships expected by chance, while leaving

318 unaltered the effects of all other predictors, keeping the same structure in the additive

319 genetic matrix, and the same distribution of maternal relationships among individuals

320 (Figure 3). 
For $\mathrm{m}^{2}$ intercept, all permutations had estimates lower than the observed data (Table 3;

322 Figure 3), suggesting that the observed effects cannot be explained by chance. The same

323 pattern was replicated when group was included in the model instead of group size or only

324 a single site was used (Table S12, S13). These results confirm a non-zero contribution of

325 maternal effects to the cortisol phenotypes of wild chimpanzees. All other observed

326 coefficients of genetic or non-genetic maternal effects were in the same range as those

327 derived from random permutations (Table 3).

We also used permutations to test whether the observed difference between the

329 variance explained by the maternal and genetic effects can occur because of chance alone.

330 None of the permutations indicated a higher difference between the variance explained by

331 maternal and genetic effects than those observed in the data in either the model with group

332 size (Figure 4) or the model with community included as a predictor (Figure S8). We

333 conclude that the maternal environment is more influential than genetics in shaping

334 cortisol responses in wild chimpanzees. 
341 Table 3: Summary of genetic $\left(\mathrm{h}^{2}\right)$ and maternal $\left(\mathrm{m}^{2}\right)$ effect estimates on circadian cortisol responses in

342 wild chimpanzees. Each coefficient represents a different component of the circadian cortisol response.

343 We also report the proportion of permutations for which these coefficient estimates were larger than

344 in the observed data. Coefficients in bold were larger in our observed data than in at least 95\% of our

345 random permutations.

\begin{tabular}{|c|c|c|c|}
\hline Coefficient & Estimate & (ICI, uCI) & $\begin{array}{c}\text { Proportion } \\
\text { observed } \\
\text { permutations }\end{array}$ \\
\hline \multicolumn{4}{|c|}{ Genetic effect } \\
\hline $\mathrm{h}^{2}$ intercept & 0.01 & $(0.00,0.06)$ & 0.92 \\
\hline $\mathrm{h}^{2}$ linear & 0.06 & $(0.00,0.42)$ & 0.84 \\
\hline $\mathrm{h}^{2}$ quadratic & 0.04 & $(0.00,0.36)$ & 0.90 \\
\hline \multicolumn{4}{|c|}{ Maternal effect } \\
\hline $\mathbf{m}^{2}$ intercept & 0.10 & $(0.02,0.18)$ & 0.00 \\
\hline $\mathrm{m}^{2}$ linear & 0.09 & $(0.00,0.51)$ & 0.22 \\
\hline $\mathrm{m}^{2}$ quadratic & 0.03 & $(0.00,0.27)$ & 0.06 \\
\hline
\end{tabular}




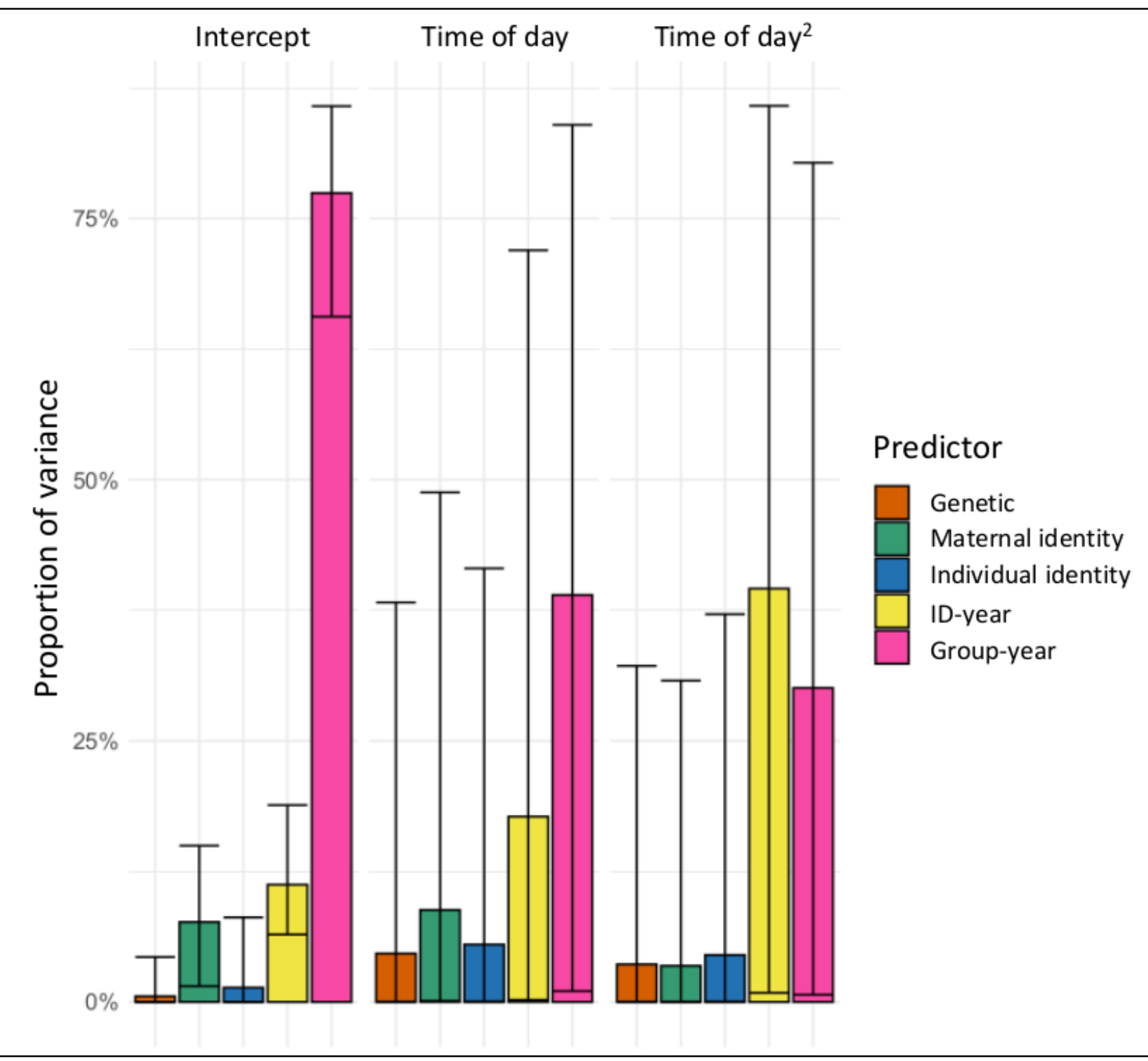

349 Figure 2: Estimates for the proportion of variance among the random effects in our model 350 examining variation in circadian cortisol responses in wild chimpanzees. The error bars 351 represent the 95\% credible interval range of the estimates. 
bioRxiv preprint doi: https://doi.org/10.1101/2021.07.16.452609; this version posted July 16, 2021. The copyright holder for this preprint (which was not certified by peer review) is the author/funder, who has granted bioRxiv a license to display the preprint in perpetuity. It is made available under aCC-BY-NC-ND 4.0 International license.

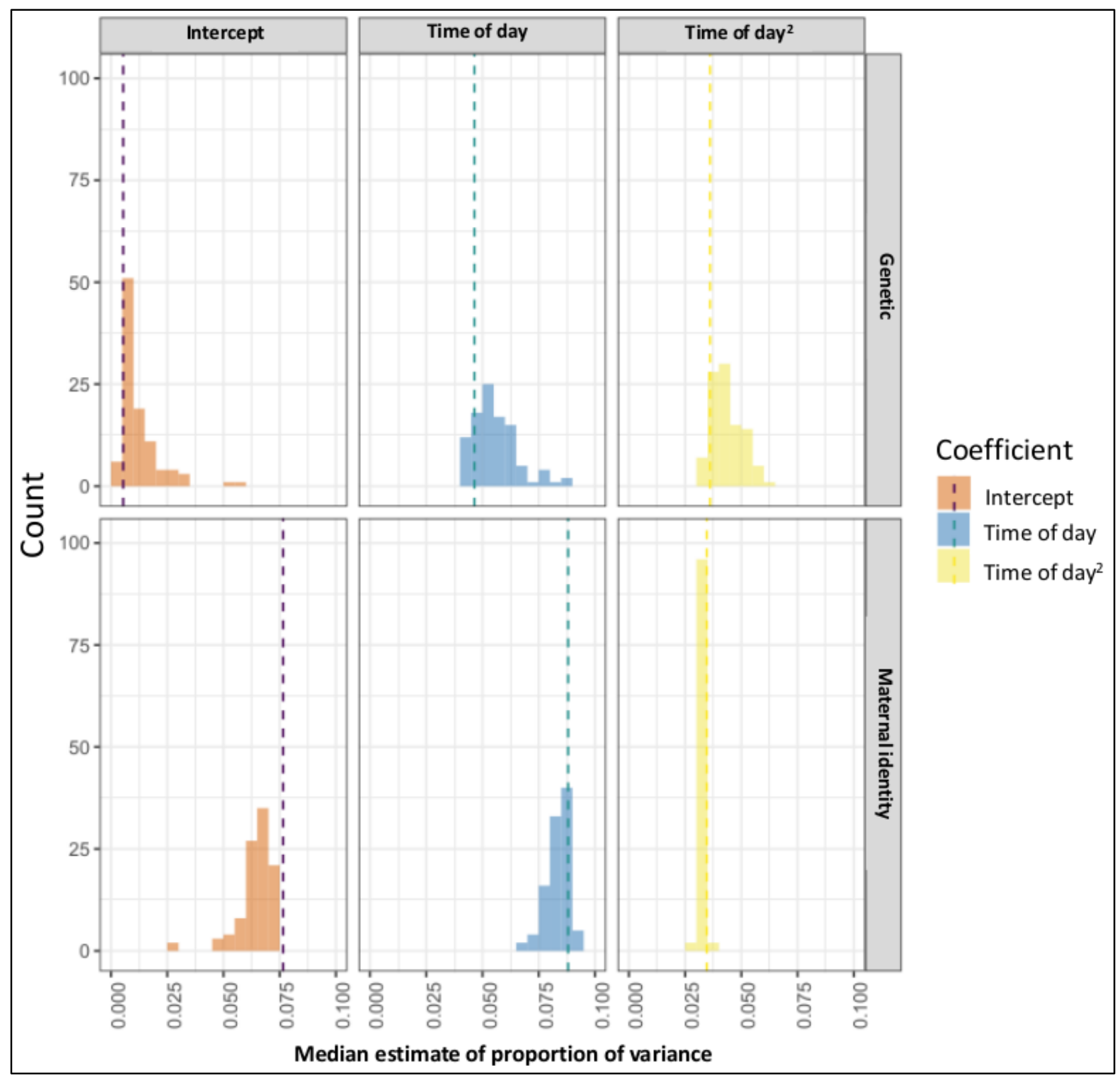

353 Figure 3: Median proportion of variance estimates obtained from the observed data (dashed vertical lines) versus estimates obtained by 100 datasets with permuted genetic relationships between individuals. Histograms represent the counts of each estimate value from the permutations. In this permutation analysis, the proportion of variance calculations includes all random effects, including our technical predictor, "project identity". Our final reported maternal effect estimate is higher than presented here as we consider only the biological predictors in that calculation. Figure S9 in the supplementary materials illustrates the permutations of all variance components in our heritability model. 
bioRxiv preprint doi: https://doi.org/10.1101/2021.07.16.452609; this version posted July 16, 2021. The copyright holder for this preprint (which

was not certified by peer review) is the author/funder, who has granted bioRxiv a license to display the preprint in perpetuity. It is made available under aCC-BY-NC-ND 4.0 International license.

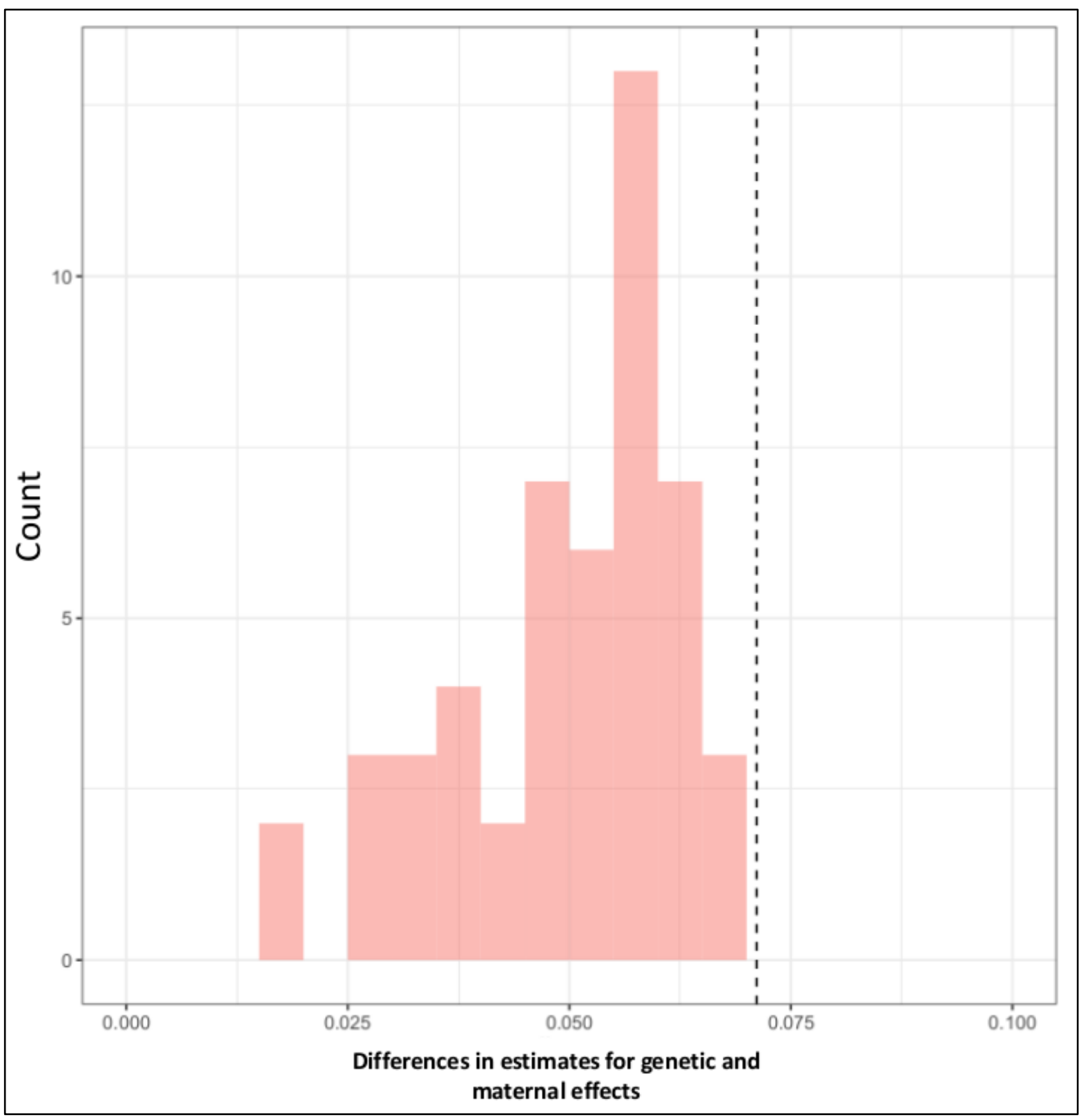

364 Figure 4: Estimates of the difference in the proportion of variance explained by the maternal effect 365 and that explained by genetic factors in the observed data (dashed line) and in 100 permutations of 366 the data (red histogram). 


\section{Discussion (1,525 words)}

Our study leverages almost two decades of long-term data collection of more than

3716,000 urine samples from 170 individuals to identify consistent individual differences in

372 circadian cortisol responses in wild chimpanzees. Using this unique dataset, we find that

373 the maternal environment has a primary role in shaping circadian cortisol phenotypes in

374 this species, certainly when compared to the influence of genetic factors. Our results are

375 robust to different model structures and are corroborated by permutations of the data

376 which indicate our maternal and genetic effect estimates are not artefacts of group

377 structures. Our study shows the importance of long-term data collection in the wild,

378 especially for long-lived species, and raises important biological questions about the nature

379 of the non-genetic maternal effects we documented. We estimated that $\sim 10 \%$ of variation

380 in average cortisol levels (conditional on the effect of time of day), is due to these maternal

381 factors.

In our study, much of the variation in urinary cortisol levels was attributable to

383 short-term group-level ("group-year" random effect) and individual-level ("ID-year"

384 random effect) factors. This finding illustrates the flexibility of these phenotypes in wild

385 animals, which vary due to food availability (Wessling et al., 2018a), dominance hierarchy

386 instability (Preis et al., 2019), reproductive state (Emery Thompson et al., 2010) or age

387 (Emery Thompson et al., 2020). While we attempted to control for such factors (see

388 Materials and Methods), our non-invasive and non-experimental approach inherently

389 contributed unidentifiable confounds that might well explain variation in cortisol

390 phenotypes. For example, short-term elevations in cortisol levels can occur in chimpanzees 
391 following single aggressive encounters (Wittig et al., 2015) or disturbance from

392 neighboring communities of conspecifics (Samuni et al., 2019), and inter-individual

393 differences exist in the magnitude of these elevations depending on the amount of social

394 support available to them (Wittig et al., 2016). Given these potential confounds, it is notable

395 that we were able to identify such a clear maternal effect in our study. Although absence of

396 evidence is not evidence of absence, the lack of a clear genetic effect in our results at least

397 indicates a qualitatively stronger influence of maternal identity in shaping cortisol

398 phenotypes in our study population. In a recent meta-analysis, Moore et al (2019) found a

399 limited role for parental care in shaping the strength of parental effects on trait variation.

400 However, as far as we are aware, few species included in the study demonstrate the

401 prolonged mother-offspring association observed in chimpanzees. We hope that our results

402 will encourage studies in other animals with protracted developmental phases or maternal

403 associations to compare and contrast the relative influence of mothers and genetic

404 inheritance.

406 environment, such as protracted maternal care or epigenetic processes, merits further

407 study. Chimpanzees have slow life histories, characterized by long gestation and

408 maturation relative to lifespan (Bründl et al., 2021), as well as prolonged dependency on

409 maternal care (Crockford et al., 2020; Nakamura et al., 2014; Samuni et al., 2020; Stanton et

410 al., 2020). Recent evidence suggests that adult female chimpanzees, and thus mothers, have

411 both relatively stable dominance hierarchies compared to males (Mielke et al., 2019) and

412 consistent individual differences in social phenotypes that endure over several years

413 (Tkaczynski et al., 2020b). As offspring associate almost permanently with their mothers 
414 until around the age of 12 years (Reddy and Sandel, 2020), maternal social phenotype is

415 the key determinant of the social environment of immature offspring. As some mothers are

416 more consistently gregarious than others (Tkaczynski et al., 2020b), and social settings

417 likely impact rates of exposure to social stressors for offspring (Sabbi et al., 2021;

418 Tkaczynski et al., 2020a), maternal effects on average cortisol levels are perhaps not

419 surprising in immature individuals. However, the maternal effects observed in our study

420 apply for individuals of all age classes, suggesting that they endure beyond the immature

421 phase.

Based on their dominance rank and social phenotypes, mothers likely vary in their

423 ability to secure feeding resources for their offspring, and this may have lifelong

424 consequences for the growth and the foraging skills of their offspring (Estienne et al., 2019;

425 Samuni et al., 2020). Previous research suggests maternal dominance status influences

426 fecal GC levels in male, but not female immature chimpanzees (Murray et al., 2018),

427 therefore, status alone is unlikely to explain the full extent of the maternal effect identified

428 in our study. If mothers vary in their rates of direct social interaction with their offspring

429 and others, via grooming or food sharing for example, offspring may learn variable social or

430 technical skills, such as extractive foraging (Estienne et al., 2019). The stable social

431 phenotypes observed in adult chimpanzees includes rates of aggression, with some

432 individuals being consistently more aggressive than others over the lifespan (Tkaczynski et

433 al., 2020b). Therefore, long-term mother-offspring association may also behaviorally prime

434 offspring on how to deal with social antagonism or other social challenges. As chimpanzees

435 are long-lived, offspring that remain in their natal group (i.e., all males and a small

436 percentage of females) may even inherit certain social relationships or components of their 
437 mother's social networks (Langergraber et al., 2013). Therefore, maternal effects may

438 influence the social and ecological environment of offspring throughout their life, as well as

439 prime how they react to these environments on a physiological and behavioral level.

In rodents, early life adversity, such as maternal neglect or loss, can induce hyper-

441 methylation of DNA regions coding for GC receptors, leading to lifelong alterations in the

442 sensitivity of these receptors and thus affecting GC feedback loops and overall GC levels

443 (Champagne and Curley, 2009; Zhang et al., 2013). In long-lived primates, including in

444 humans, early life adversity can lead to long-term alteration of HPA axis activity (Berens et

445 al., 2017; Ehrlich et al., 2016; Rosenbaum et al., 2020). Indeed, in wild baboons, early life

446 adversity can have intergenerational effects on survival, i.e., if a mother experiences

447 adversity, both she and her offspring can experience reduced survival outcomes (Zipple et

448 al., 2019), which may be explained by the GC effects of adversity. Recent meta-analyses and

449 evidence from long-term field studies now suggest that, at least for long-lived species,

450 elevated HPA axis activity over the lifespan is a predictor of survival (Bonier et al., 2009;

451 Campos et al., 2021; Schoenle et al., 2021). However, in wild chimpanzees, although

452 maternal loss impacts later life reproductive success (Crockford et al., 2020), there is no

453 evidence that this is the result of long-term HPA axis activity alteration as effects on

454 circadian cortisol patterns following maternal loss do not endure into adulthood (Girard-

455 Buttoz et al., 2021). This time-limited nature of alteration of the HPA axis activity suggests

456 that adversity may not have a clear epigenetic effect on HPA axis activity in this species, at

457 least among young orphan individuals that later survive into adulthood. Whether the

458 enduring maternal effect observed in our study is due to early life epigenetic maternal

459 effects, or whether it is the result of the aforementioned behavioral priming, will not be 
460 trivial to disentangle. Behavioral observations can help determine whether mother-

461 offspring dyads and maternal siblings are exposed to similar levels of social stressors, or

462 whether the same dyads and siblings behaviorally respond to stressors in a similar way.

463 Although this would not eliminate the possibility of epigenetic effects, it would allow

464 empirical testing for evidence of behavioral priming.

In our study, the contribution of heritable factors to cortisol phenotypes was low as

467 more controlled laboratory (e.g. 28\%; Houslay et al., 2019) or wild experimental animal

468 studies (e.g. 40\%; Bairos-Novak et al., 2018) in which GC variation was directly

469 manipulated by the observers. Indeed, our analysis revealed an extremely low and unstable

470 estimate of the contribution of genetics to variation in chimpanzee cortisol phenotypes,

471 contrary to our predictions. Human research involves more controlled sampling than can

472 be achieved with wild animals, especially when non-invasive and non-experimental

473 methods are used, as in our study. To address this methodological challenge, we employed

474 strict criteria for the inclusion of individuals into the study to ensure we could accurately

475 characterize their cortisol phenotypes. We required that each individual have at least one

476 year of sampling in which we had samples spanning the majority of the day (i.e., morning,

477 midday, and evening samples) in order to measure circadian responses and their

478 repeatability. Employing such criteria reduced the number of individuals we could include

479 in the study, and all individuals were spread across five separate groups and two different

480 populations (note that we repeated our analysis solely within the larger of these two

481 populations, finding qualitatively similar results despite the reduced overall sample size;

482 Table S12 in Supplementary Materials). Chimpanzees are also a long-lived species with low 
483 fertility. Consequently, despite working with data from two of the longest running wild

484 chimpanzee field sites (Reynolds, 2005; Wittig and Boesch, 2019), our pedigree is relatively

485 shallow for this form of analysis, including relatively few third-generation individuals.

486 Despite these challenges, our study reveals new insights on how cortisol phenotypes vary

487 across different demographics of wild chimpanzees, and the prominent role of maternal

488 effects in shaping these differences.

Previous studies examining the repeatability of circadian cortisol responses in

490 chimpanzees focused exclusively on adult males (Sonnweber et al., 2018); in our study we

491 were able to show that individual circadian cortisol responses are repeatable across

492 demographics, including adult females in various reproductive states and in immature

493 individuals. However, we only found strong support only for consistent individual

494 differences in average cortisol levels, rather than circadian slopes. This difference from the

495 findings in Sonnweber et al. (2018) was not driven by the inclusion of adult females and

496 immature individuals, as in our separate adult male repeatability analysis, we again found

497 weak support for consistent individual differences in circadian slopes. Within our adult

498 male only analysis, as compared to Sonnweber et al. (2018), we included substantially

499 more samples and individuals, despite using stricter criteria for individual inclusion.

500 Circadian slopes vary with experiences of adversity, including maternal loss and illness

501 (Behringer et al., 2020; Girard-Buttoz et al., 2021), and also change with aging and life

502 history stages in chimpanzees (Emery Thompson et al., 2020). Therefore, our uncertain

503 repeatability estimates for circadian slopes could be due to substantial within-individual

504 variation. Given our study included only healthy chimpanzees and modelled age effects, it

505 seems more likely that our uncertain repeatability estimates for slopes are the result of low 
506 between-individual variation for this particular component of circadian cortisol

507 phenotypes.

To conclude, in our study, the maternal environment is the main early life influence

509 on cortisol regulation throughout the lifespan in chimpanzees. Whether this is due to

510 epigenetic processes early in development, or due to behavioral priming of how to deal

511 with the ecological or social environment, clearly merits further investigation and will

512 contribute to our understanding of the role of parents and developmental plasticity in long-

513 lived species. Indeed, determining whether this maternal effect on cortisol regulation has

514 been specifically selected for, or is instead a by-product of extended maternal association,

515 will be key to understanding prolonged development and parental dependency as a life

516 history adaptation.

\section{Materials \& Methods}

519 Study Site \& Subjects

520 In both Taï and Budongo, data on the chimpanzees are systematically collected by a

521 combination of locally-employed field assistants and visiting researchers. Longitudinal data

522 includes daily counts of group compositions, as well as recording of behavioral and social

523 interactions using a combination of focal observations and ad-libitum sampling (Altmann, 1974).

524 During observations of the chimpanzees, observers opportunistically collected urine and fecal

525 samples from identifiable individuals. In Taï, regular observations of the chimpanzees commenced

526 in 1990 (North, 1990-present; South, 1999-present; East, 2007-present (Wittig and Boesch,

527 2019)) and regular urine sample collection (see below) commenced in 2000 (North and South, 
528 2000-present; East, 2003-present). In Budongo, regular observations of the chimpanzees

529 commenced in 1994 (Sonso, 1994-present; Waibira, 2011-present; (Reynolds, 2005; Samuni et al.,

5302014 )) and regular urine sample collection commenced in 2005 (Sonso, 2005-present; Waibira,

531 2017-present).

533 Urine Sample Collection and Analysis

534 We collected urine from identifiable individuals using a plastic pipette to transfer urine

535 from the ground or vegetation into a $5 \mathrm{ml}$ cryovial. Cryovials were stored in liquid nitrogen once

536 back in camp, typically within 12 hours of collection. Frozen samples were transported packed in

537 dry ice to the Max Planck Institute for Evolutionary Anthropology in Leipzig, Germany, where they

538 were stored at $\leq 20^{\circ} \mathrm{C}$ in freezers.

539 We quantified urinary cortisol levels for each sample using LCMS ((Hauser et al., 2008)) and

540 MassLynx (version 4.1; QuanLynx-Software). We used prednisolone (coded as "old method" in

541 models, i.e. most samples analyzed prior to July 2016; Hauser et al., 2008), or testosterone d4 ("new

542 method", i.e. all samples analyzed post September 2016; Wessling et al., 2018b) as the internal

543 standards. For each sample, we measured specific gravity (SG) using a refractometer (TEC, Ober-

544 Ramstadt, Germany). SG values were used to correct cortisol measurements for variation in water

545 content in the urine using the formula outlined by Miller et al. (2004):

SGcorrectedcortisol $=$ rawhormoneconcentrationx $\frac{\left(S G_{\text {populationmean }}-1.0\right)}{\left(S G_{\text {sample }}-1.0\right)}$

547 The population means were derived from the samples included in this analysis. The SG

548 population mean was 1.02 for Taï and 1.02 for Budongo. 
550 Fecal Sample Collection and Pedigree Generation

$551 \quad$ Fecal samples were collected from identifiable individuals. The samples were collected

552 using plastic bags and then either directly stored in ethanol, dried on silica gel, or using a two-step

553 ethanol-silica method (Nsubuga et al., 2004). Dried samples were transported in silica to the Max

554 Planck Institute for Evolutionary Anthropology in Leipzig, Germany. Approximately 100mg of each

555 sample was extracted using either the QIAamp DNA stool (Qiagen) or the GeneMATRIX Stool DNA

556 Purification (Roboklon) kits. We genotyped DNA extracts using a two-step amplification method

557 including 19 microsatellite loci as detailed previously (Arandjelovic et al., 2009). Using CERVUS 3.0

558 software (Kalinowski et al., 2007), we compared the resultant genotypes using the 'identity

559 analysis' function to confirm individual identities and the 'parentage analysis' function to confirm

560 maternities and assign paternities.

563 To provide an accurate measure of circadian patterns for each individual, we excluded

564 certain samples where cortisol levels were expected to be elevated and not representative of

565 normal circadian patterning. Here, we provide a detailed description of the sample exclusion

566 process.

567 In female primates, including chimpanzees, cortisol levels vary with reproductive state

568 (Brent et al., 2011; Cohen et al., 1958; Emery Thompson et al., 2010). Chimpanzee gestation is

569 approximately 240 days (Peacock and Rogers, 1959). Using demography data and the birth dates of

570 offspring, we assigned females to three reproductive states (Emery Thompson et al., 2010): 
571 pregnant (during the 240 days preceding the birth of any offspring), lactating (the 1,095 days

572 [based on average resumption of cycling in the population] subsequent to the birth of any

573 offspring) and cycling (any other period of time when females were not assigned as pregnant or

574 lactating). We included all adult female samples where we were able to assign reproductive state to

575 the female at the time of sampling (Kahlenberg et al., 2008). Furthermore, following related studies

576 (Emery Thompson et al., 2020, 2010), we excluded samples from pregnant females because cortisol

577 levels tend to increase during pregnancy. In fact, interactions can occur between maternal and fetal

578 HPA axes making it difficult to accurately determine maternal cortisol levels in isolation (Smith and

579 Thomson, 1991).

In immature chimpanzees ( $<12$ years old), maternal separation elevates cortisol secretion

581 and has short-term effects on cortisol circadian patterns (Girard-Buttoz et al., 2021). Therefore, if

582 immature individuals lost their mother prior to the age of 12 years old (social maturity), we

583 excluded any sample collected from them following maternal loss during immaturity. However, as

584 there is no evidence of long-term impacts of maternal loss in mature chimpanzees (Girard-Buttoz et

585 al., 2021), all mature individuals were included regardless of maternal loss during immaturity.

586 Furthermore, injury and sickness can elevate cortisol levels in primates (Barton, 1987; Behringer et

587 al., 2020; McIntosh, 1987; Muehlenbein and Watts, 2010) and affect circadian cortisol patterns in

588 chimpanzees (Behringer et al., 2020). Therefore, we excluded samples from individuals that

589 displayed symptoms of sickness or injury (determined by onsite veterinarians in each field site).

590 Lastly, there is a link between dominance rank and GC levels in male and female

591 chimpanzees (Markham et al., 2014; Muller and Wrangham, 2004). However, for one group in our

592 study (Waibira), we had insufficient data to calculate ranks for the females, and in all groups, for

593 immature individuals it is unclear whether maternal rank influences their cortisol levels. Given

594 these caveats, we did not assign ranks or include this as a variable in our analyses when combing 
595 demographics. However, when we analyzed repeatability in the demographics separately, for the

596 adult male analysis, we included dominance rank as a fixed effect in those models. Male dominance

597 ranks were calculated using pant grunt vocalizations, a unidirectional call given from subordinate

598 individuals (Wittig and Boesch, 2003). We used a likelihood-based adaptation of the Elo rating

599 approach to calculate ranks (Foerster et al., 2016; Mielke et al., 2018; Neumann et al., 2011); we

600 assigned continuous Elo ranks to subjects for each day of sampling; each score was standardized

601 between 0 (lowest rank) and 1 (highest rank) within each group. By pooling males, females, and

602 immature individuals together without the inclusion of dominance rank in our heritability analysis,

603 our estimates of heritable contributions to those differences are likely more conservative.

To ensure that we were able to characterize circadian cortisol patterns for each individual,

605 we only included individuals with a minimum of 3 urine samples per year, collected during both

606 morning and afternoon hours, such that the earliest and latest samples were separated by at least 6

607 hours.

To accurately model circadian patterns of cortisol for all individuals (our measure of

609 cortisol reaction norm), we included interactions between the linear and quadratic time variables

610 and all other fixed effects. We used 12 years of age to distinguish between adult (aged >=12 years)

611 and immature individuals (aged $<12$ years), as it is the age at which individuals socialize and forage

612 predominantly independent from their mothers (Reddy and Sandel, 2020). In addition to the

613 demographic categorization (adult male, cycling female, lactating female, immature male, immature

614 female) and age of each individual on the day of sampling, we included in the analysis a number of

615 control variables known to influence cortisol levels. Both group size and mating competition

616 (Emery Thompson et al., 2010; Muller and Wrangham, 2004; Preis et al., 2019; Samuni et al., 2019)

617 can affect GC levels in primates, therefore, we calculated both the number of adults (mean[+SD];

618 East 13.81[+2.19], North 8.92[+1.33], South 16.52[+2.58], Sonso 36.35[+4.12], Waibira 
$61954.11[+2.50])$ and the male-to-female sex-ratio (mean[+SD]; East 0.35[+0.12], North $0.50[+0.19]$,

620 South $0.37[+0.10]$, Sonso $0.49[+0.05]$, Waibira $1.02[+0.02])$ at the time of sampling for each sample.

621 Lastly, as seasonal variation in rainfall, temperature, humidity and food availability can influence

622 cortisol levels in chimpanzees (Wessling et al., 2018a), we accounted for this circannual variation

623 by converting the Julian date of sampling into a circular variable and including its sine and cosine in

624 our models (Stolwijk et al., 1999; Wessling et al., 2018a, 2018b).

626 Notes on Model Fitting and Verification

627 All data preparation, models and analyses were performed using R version 3.6.1 (R Core

628 Team, 2020). Prior to testing our models, we applied the vif function of the 'car' R package (Fox and

629 Weisberg, 2011) to linear model versions of our mixed models (i.e. lacking random effects) to test

630 for any collinearity issues via examination of variance inflation factors (VIF). There were issues

631 with collinearity if either "site" or "group" were included in the models as both variables were

632 either collinear with each other or with "group size". Therefore, we retained just "group size", with

633 all remaining VIFs $<2.90$. The "group-year" variable was also included as a random effect to

634 account for group-level confounds. Furthermore, for the heritability analyses, we performed

635 additional analyses using models containing "group" as a predictor, finding no qualitative

636 differences in our animal model estimates (see Table S12).

637 All models were fitted with a Gaussian error distribution using the R package 'brms'

638 (Hadfield, 2019). For all models, numeric variables were standardized as z-scores. We fit models

639 with weakly regularising priors for the fixed effects $(\beta \sim \operatorname{Normal}(0,1))$ and for the random effects

640 (student t-distributed $(3,0,10)$ ), with uniform $(\operatorname{LKJ}(1))$ priors for covariance matrices of the

641 random slopes. For all models, we specified four chains of 4,000 iterations, half of which were 
642 devoted to the warm-up. Sampling diagnostics (Rhat $<1.1$ ) and trace plots confirmed chain

643 convergence for all models. Effective sample sizes confirmed no issues with autocorrelation of

644 sampling for all models.

645 We estimated the heritability of urinary cortisol levels and their circadian patterning by

646 fitting an "animal model", which estimates additive genetic variance in a trait by including the

647 pedigree of individuals as a random effect (Wilson et al., 2010). Pedigrees were generated with the

648 R package 'MasterBayes' (Hadfield, 2017). The additive genetic matrix was computed using the

649 Amatrix function of the R package 'AGHmatrix' (Amadeu et al., 2016).

651 Data availability

652 All data used in the analyses presented are available via Figshare

653 (https://doi.org/10.6084/m9.figshare.13720765.v1).

655 Competing Interests

656 We have no competing interests to report.

657 Acknowledgments

658 We thank the Ministère de l'Enseignement Supérieur et de la Recherche Scientifique, the

659 Ministère de Eaux et Fôrests in Côte d'Ivoire, the Office Ivoirien des Parcs et Réserves, the

660 Uganda Wildlife Authority and the Uganda National Council for Science and Technology for

661 permitting the study. In Côte d'Ivoire, we are grateful to the Centre Suisse de Recherches 
662 Scientifiques en Côte d'Ivoire and the staff members of the Taï Chimpanzee Project for their

663 support. In Uganda, we thank the management and staff of the Budongo Conservation Field

664 Station. We are indebted to the efforts of Christophe Boesch and Vernon Reynolds in the

665 establishments of the study field sites and their contributions to years of data collection.

666 We also thank the many field and research assistants that help generate the data for this

667 project. We are extremely grateful for the work conducted in the laboratories of Tobias

668 Deschner and Linda Vigilant in the Max Planck Institute of Evolutionary Anthropology,

669 Leipzig, Germany, specifically the efforts of Róisín Murtagh, Vera Schmeling, Janette

670 Gleiche, Anette Nicklisch, Juliane Damm, Carolyn Rowney, and Jared Cobain. We also thank

671 Ruth Sonnweber and Verena Behringer for useful discussions on the topic.

672 Funding

673 This study was funded by the Max Planck Society and the European Research Council (ERC)

674 under the European Union's Horizon 2020 research and innovation program awarded to

675 CC (grant agreement no. 679787). LS was supported by the Minerva Foundation, CYA and

676 AP received funding from the LSB Leakey Foundation, CYA also received funding from

677 Subvention Egalité (University of Neuchâtel, Switzerland) and Fonds des Donations

678 (University of Neuchâtel, Switzerland). CG was supported by the Wenner-Gren Foundation.

679 VM was supported by a grant of Deutsche Forschungsgemeinschaft (DFG) granted to RMW

680 (WI 2637/3-1). 


\section{Author Contributions}

682 CC, CGB, FM and PJT conceived the study. AP, CC, CG, CGB, CYA, EGW, LS, LW, PF, PJT, PDV, 683 RMW, TD, TL, VM, and ZS collected data. TD, LS, CH, KZ, CC, and RMW provided long-term 684 data. PJT, FM, CC, CGB, PF, TD and RMW helped design the study; FM, CGB and PT 685 performed the statistical analyses; TD oversaw the laboratory analyses; LV supervised and 686 conducted genetic parentage analyses; PT wrote the first draft of the manuscript, all 687 authors contributed to subsequent editing.

\section{References}

690

691

692

693

694

695

696

697

698

699

700

701

702

703

704

705

706

707

708

709

710

711

712
Arandjelovic M, Guschanski K, Schubert G, Harris TR, Thalmann O, Siedel H, Vigilant L. 2009. Two-step multiplex polymerase chain reaction improves the speed and accuracy of genotyping using DNA from noninvasive and museum samples. Molecular Ecology Resources 9:28-36. doi:10.1111/j.1755-0998.2008.02387.x Araya-Ajoy YG, Dingemanse NJ. 2017. Repeatability, heritability, and age-dependence of seasonal plasticity in aggressiveness in a wild passerine bird. J Anim Ecol 86:227238. doi:10.1111/1365-2656.12621

Araya-Ajoy YG, Mathot KJ, Dingemanse NJ. 2015. An approach to estimate short-term, longterm and reaction norm repeatability. Methods in Ecology and Evolution 6:14621473. doi:10.1111/2041-210X.12430

Bairos-Novak KR, Ryan CP, Freeman AR, Anderson WG, Hare JF. 2018. Like mother, like daughter: heritability of female Richardson's ground squirrel Urocitellus richardsonii cortisol stress responses. Curr Zool 64:153-163. doi:10.1093/cz/zox014

Bartels M, de Geus EJC, Kirschbaum C, Sluyter F, Boomsma DI. 2003a. Heritability of Daytime Cortisol Levels in Children. Behav Genet 33:421-433. doi:10.1023/A:1025321609994

Bartels M, Van den Berg M, Sluyter F, Boomsma DI, de Geus EJC. 2003b. Heritability of cortisol levels: review and simultaneous analysis of twin studies. Psychoneuroendocrinology 28:121-137. doi:10.1016/S0306-4530(02)00003-3

Barton RN. 1987. 6 - The neuroendocrinology of physical injury. Baillière's Clinical Endocrinology and Metabolism, Neuroendocrinology of Stress 1:355-374. doi:10.1016/S0950-351X(87)80067-8 
Baugh AT, Oers K van, Dingemanse NJ, Hau M. 2014. Baseline and stress-induced glucocorticoid concentrations are not repeatable but covary within individual great tits (Parus major). General and Comparative Endocrinology 208:154-163. doi:10.1016/j.ygcen.2014.08.014

Beehner JC, Bergman TJ. 2017. The next step for stress research in primates: To identify relationships between glucocorticoid secretion and fitness. Horm Behav 91:68-83. doi:10.1016/j.yhbeh.2017.03.003

Behringer V, Preis A, Wu DF, Crockford C, Leendertz FH, Wittig RM, Deschner T. 2020. Urinary Cortisol Increases During a Respiratory Outbreak in Wild Chimpanzees. Front Vet Sci 7. doi:10.3389/fvets.2020.00485

Berens AE, Jensen SKG, Nelson CA. 2017. Biological embedding of childhood adversity: from physiological mechanisms to clinical implications. BMC Medicine 15:135. doi:10.1186/s12916-017-0895-4

Bonier F, Cox RM. 2020. Do hormone manipulations reduce fitness? A meta-analytic test of the Optimal Endocrine Phenotype Hypothesis. Molecular and Cellular Endocrinology 500:110640. doi:10.1016/j.mce.2019.110640

Bonier F, Martin PR. 2016. How can we estimate natural selection on endocrine traits? Lessons from evolutionary biology. Proc R Soc B 283:20161887. doi:10.1098/rspb.2016.1887

Bonier F, Martin PR, Moore IT, Wingfield JC. 2009. Do baseline glucocorticoids predict fitness? Trends in Ecology \& Evolution 24:634-642. doi:10.1016/j.tree.2009.04.013

Brent LJN, Semple S, Dubuc C, Heistermann M, MacLarnon A. 2011. Social capital and physiological stress levels in free-ranging adult female rhesus macaques. Physiology \& Behavior 102:76-83. doi:10.1016/j.physbeh.2010.09.022

Bründl AC, Tkaczynski PJ, Kohou GN, Boesch C, Wittig RM, Crockford C. 2021. Systematic mapping of developmental milestones in wild chimpanzees. Developmental Science 24:e12988. doi:https://doi.org/10.1111/desc.12988

Butler K, Klaus K, Edwards L, Pennington K. 2017. Elevated cortisol awakening response associated with early life stress and impaired executive function in healthy adult males. Hormones and Behavior 95:13-21. doi:10.1016/j.yhbeh.2017.07.013

Campos FA, Archie EA, Gesquiere LR, Tung J, Altmann J, Alberts SC. 2021. Glucocorticoid exposure predicts survival in female baboons. Science Advances 7:eabf6759. doi:10.1126/sciadv.abf6759

Carrion VG, Weems CF, Ray RD, Glaser B, Hessl D, Reiss AL. 2002. Diurnal salivary cortisol in pediatric posttraumatic stress disorder. Biological Psychiatry 51:575-582. doi:10.1016/S0006-3223(01)01310-5

Champagne FA. 2008. Epigenetic mechanisms and the transgenerational effects of maternal care. Frontiers in Neuroendocrinology, Special Issue: Epigenetics 29:386-397. doi:10.1016/j.yfrne.2008.03.003

Champagne FA, Curley JP. 2009. Epigenetic mechanisms mediating the long-term effects of maternal care on development. Neuroscience \& Biobehavioral Reviews, Risk Factors for Mental Health: Translational Models from Behavioral Neuroscience 33:593-600. doi:10.1016/j.neubiorev.2007.10.009

Cohen M, Stiefel M, Reddy WJ, Laidlaw JC. 1958. The secretion and disposition of cortisol during pregnancy. None 18:1076-1092. doi:10.1210/jcem-18-10-1076 
Cook KV, O'Connor CM, McConnachie SH, Gilmour KM, Cooke SJ. 2012. Condition dependent intra-individual repeatability of stress-induced cortisol in a freshwater fish. Comp Biochem Physiol, Part A Mol Integr Physiol 161:337-343. doi:10.1016/j.cbpa.2011.12.002

764

Corbett BA, Mendoza S, Abdullah M, Wegelin JA, Levine S. 2006. Cortisol circadian rhythms and response to stress in children with autism. Psychoneuroendocrinology 31:59-68. doi:10.1016/j.psyneuen.2005.05.011

Crockford C, Samuni L, Vigilant L, Wittig RM. 2020. Postweaning maternal care increases male chimpanzee reproductive success. Science Advances 6:eaaz5746. doi:10.1126/sciadv.aaz5746

Dingemanse NJ, Dochtermann NA. 2013. Quantifying individual variation in behaviour: mixed-effect modelling approaches. Journal of Animal Ecology 82:39-54. doi:10.1111/1365-2656.12013

Ehrlich KB, Ross KM, Chen E, Miller GE. 2016. Testing the biological embedding hypothesis: Is early life adversity associated with a later proinflammatory phenotype? Dev Psychopathol 28:1273-1283. doi:10.1017/S0954579416000845

Emery Thompson M, Fox SA, Berghänel A, Sabbi KH, Phillips-Garcia S, Enigk DK, Otali E, Machanda ZP, Wrangham RW, Muller MN. 2020. Wild chimpanzees exhibit humanlike aging of glucocorticoid regulation. PNAS 117:8424-8430. doi:10.1073/pnas.1920593117

Emery Thompson M, Muller MN, Kahlenberg SM, Wrangham RW. 2010. Dynamics of social and energetic stress in wild female chimpanzees. Hormones and Behavior 58:440449. doi:10.1016/j.yhbeh.2010.05.009

Estienne V, Cohen H, Wittig RM, Boesch C. 2019. Maternal influence on the development of nut-cracking skills in the chimpanzees of the Taï forest, Côte d'Ivoire (Pan troglodytes verus). American Journal of Primatology 81:e23022. doi:https://doi.org/10.1002/ajp.23022

Foerster S, Franz M, Murray CM, Gilby IC, Feldblum JT, Walker KK, Pusey AE. 2016. Chimpanzee females queue but males compete for social status. Scientific Reports 6:35404. doi:10.1038/srep35404

Fox J, Weisberg S. 2011. An R Companion to Applied Regression. SAGE.

Girard-Buttoz C, Tkaczynski PJ, Samuni L, Fedurek P, Gomes C, Löhrich T, Manin V, Preis A, Valé P, Deschner T, Wittig RM, Crockford C. 2020. Early maternal loss affects diurnal cortisol slopes in immature but not mature wild chimpanzees. bioRxiv 2020.10.15.340893. doi:10.1101/2020.10.15.340893

Gonzalez A, Jenkins JM, Steiner M, Fleming AS. 2009. The relation between early life adversity, cortisol awakening response and diurnal salivary cortisol levels in postpartum women. Psychoneuroendocrinology 34:76-86. doi:10.1016/j.psyneuen.2008.08.012

Grace JK, Anderson DJ. 2014. Corticosterone stress response shows long-term repeatability and links to personality in free-living Nazca boobies. General and Comparative Endocrinology 208:39-48. doi:10.1016/j.ygcen.2014.08.020 and Future Directions. Integr Comp Biol 60:79-88. doi:10.1093/icb/icaa003 
802

803

804

805

806

807

808

809

810

811

812

813

814

815

816

817

818

819

820

821

822

823

824

825

826

827

828

829

830

831

832

833

834

835

836

837

838

839

840

841

842

843

844

845

846

847
Guindre-Parker S. 2018. The Evolutionary Endocrinology of Circulating Glucocorticoids in Free-Living Vertebrates: Recent Advances and Future Directions across Scales of Study. Integr Comp Biol 58:814-825. doi:10.1093/icb/icy048

Guindre-Parker S, Mcadam AG, van Kesteren F, Palme R, Boonstra R, Boutin S, Lane JE, Dantzer B. 2019. Individual variation in phenotypic plasticity of the stress axis. Biology Letters 15:20190260. doi:10.1098/rsbl.2019.0260

Gustafsson PA, Gustafsson PE, Anckarsäter H, Lichtenstein P, Ljung T, Nelson N, Larsson H. 2011. Heritability of Cortisol Regulation in Children. Twin Research and Human Genetics 14:553-561. doi:10.1375/twin.14.6.553

Gustafsson PE, Janlert U, Theorell T, Hammarström A. 2010. Life-course socioeconomic trajectories and diurnal cortisol regulation in adulthood. Psychoneuroendocrinology 35:613-623. doi:10.1016/j.psyneuen.2009.09.019

Hadfield J. 2019. MCMCglmm: MCMC Generalised Linear Mixed Models.

Hadfield J. 2017. MasterBayes: ML and MCMC Methods for Pedigree Reconstruction and Analysis.

Hauser B, Deschner T, Boesch C. 2008. Development of a liquid chromatography-tandem mass spectrometry method for the determination of 23 endogenous steroids in small quantities of primate urine. Journal of Chromatography B 862:100-112. doi:10.1016/j.jchromb.2007.11.009

Houslay TM, Earley RL, White SJ, Lammers W, Grimmer AJ, Travers LM, Johnson EL, Young AJ, Wilson AJ. 2019. Genetic integration of the stress response. bioRxiv 770586. doi:10.1101/770586

Kahlenberg SM, Thompson ME, Muller MN, Wrangham RW. 2008. Immigration costs for female chimpanzees and male protection as an immigrant counterstrategy to intrasexual aggression. Animal Behaviour 76:1497-1509. doi:10.1016/j.anbehav.2008.05.029

Kalinowski ST, Taper ML, Marshall TC. 2007. Revising how the computer program cervus accommodates genotyping error increases success in paternity assignment. Molecular Ecology 16:1099-1106. doi:10.1111/j.1365-294X.2007.03089.x

Langergraber KE, Mitani JC, Watts DP, Vigilant L. 2013. Male-female socio-spatial relationships and reproduction in wild chimpanzees. Behav Ecol Sociobiol 67:861873. doi:10.1007/s00265-013-1509-6

Maccari S, Krugers HJ, Morley-Fletcher S, Szyf M, Brunton PJ. 2014. The Consequences of Early-Life Adversity: Neurobiological, Behavioural and Epigenetic Adaptations. Journal of Neuroendocrinology 26:707-723. doi:https://doi.org/10.1111/jne.12175

Markham AC, Santymire RM, Lonsdorf EV, Heintz MR, Lipende I, Murray CM. 2014. Rank effects on social stress in lactating chimpanzees. Animal Behaviour 87:195-202. doi:10.1016/j.anbehav.2013.10.031

McIntosh TK. 1987. Prolonged Disruption of Plasma $\beta$-Endorphin Dynamics after Trauma in the Nonhuman Primate. Endocrinology 120:1734-1741. doi:10.1210/endo-1205-1734

Mielke A, Preis A, Samuni L, Gogarten JF, Wittig RM, Crockford C. 2018. Flexible decisionmaking in grooming partner choice in sooty mangabeys and chimpanzees. Royal Society Open Science 5:172143. doi:10.1098/rsos.172143

Miller RC, Brindle E, Holman DJ, Shofer J, Klein NA, Soules MR, O’Connor KA. 2004. Comparison of Specific Gravity and Creatinine for Normalizing Urinary 
Reproductive Hormone Concentrations. Clinical Chemistry 50:924-932. doi:10.1373/clinchem.2004.032292

Montiglio P-O, Garant D, Pelletier F, Réale D. 2015. Intra-individual variability in fecal cortisol metabolites varies with lifetime exploration and reproductive life history in eastern chipmunks (Tamias striatus). Behav Ecol Sociobiol 69:1-11. doi:10.1007/s00265-014-1812-x

Moore MP, Whiteman HH, Martin RA. 2019. A mother's legacy: the strength of maternal effects in animal populations. Ecology Letters 22:1620-1628. doi:10.1111/ele.13351

Muehlenbein MP, Watts DP. 2010. The costs of dominance: testosterone, cortisol and intestinal parasites in wild male chimpanzees. BioPsychoSocial Medicine 4:21. doi:10.1186/1751-0759-4-21

Muller MN, Wrangham RW. 2004. Dominance, cortisol and stress in wild chimpanzees (Pan troglodytes schweinfurthii). Behav Ecol Sociobiol 55:332-340. doi:10.1007/s00265003-0713-1

Murray CM, Stanton MA, Wellens KR, Santymire RM, Heintz MR, Lonsdorf EV. 2018. Maternal effects on offspring stress physiology in wild chimpanzees. American Journal of Primatology 80:e22525. doi:10.1002/ajp.22525

Nakagawa S, Schielzeth H. 2010. Repeatability for Gaussian and non-Gaussian data: a practical guide for biologists. Biol Rev Camb Philos Soc 85:935-956. doi:10.1111/j.1469-185X.2010.00141.x

Nakamura M, Hayaki H, Hosaka K, Itoh N, Zamma K. 2014. Brief Communication: Orphaned male Chimpanzees die young even after weaning. American Journal of Physical Anthropology 153:139-143. doi:https://doi.org/10.1002/ajpa.22411

Neumann C, Duboscq J, Dubuc C, Ginting A, Engelhardt A. 2011. Assessing dominance hierarchies: validation and advantages of progressive evaluation with Elo-rating. Animal Behaviour 82:911-921. doi:10.1016/j.anbehav.2011.07.016

Nsubuga AM, Robbins MM, Roeder AD, Morin PA, Boesch C, Vigilant L. 2004. Factors affecting the amount of genomic DNA extracted from ape faeces and the identification of an improved sample storage method. Molecular Ecology 13:20892094. doi:10.1111/j.1365-294X.2004.02207.x

Peacock LJ, Rogers CM. 1959. Gestation Period and Twinning in Chimpanzees. Science 129:959-959. doi:10.1126/science.129.3354.959

Preis A, Samuni L, Deschner T, Crockford C, Wittig RM. 2019. Urinary Cortisol, Aggression, Dominance and Competition in Wild, West African Male Chimpanzees. Front Ecol Evol 7. doi:10.3389/fevo.2019.00107

R Core Team. 2020. R: A language and environment for statistical computing. R Foundation for Statistical Computing,. Vienna, Austria.

Reddy RB, Sandel AA. 2020. Social relationships between chimpanzee sons and mothers endure but change during adolescence and adulthood. Behav Ecol Sociobiol 74:1-14. doi:10.1007/s00265-020-02937-7

Reynolds V. 2005. The Chimpanzees of the Budongo Forest: Ecology, Behaviour and Conservation. Oxford, New York: Oxford University Press.

Rosenbaum S, Zeng S, Campos FA, Gesquiere LR, Altmann J, Alberts SC, Li F, Archie EA. 2020. Social bonds do not mediate the relationship between early adversity and 
adult glucocorticoids in wild baboons. Proc Natl Acad Sci USA 117:20052-20062. doi:10.1073/pnas.2004524117

Sabbi KH, Thompson ME, Machanda ZP, Otali E, Wrangham RW, Muller MN. 2021. Sex differences in early experience and the development of aggression in wild chimpanzees. PNAS 118. doi:10.1073/pnas.2017144118

Samuni L, Mundry R, Terkel J, Zuberbühler K, Hobaiter C. 2014. Socially learned habituation to human observers in wild chimpanzees. Anim Cogn 17:997-1005. doi:10.1007/s10071-014-0731-6

Samuni L, Preis A, Deschner T, Wittig RM, Crockford C. 2019. Cortisol and oxytocin show independent activity during chimpanzee intergroup conflict. Psychoneuroendocrinology 104:165-173. doi:10.1016/j.psyneuen.2019.02.007

Samuni L, Tkaczynski P, Deschner T, Löhrrich T, Wittig RM, Crockford C. 2020. Maternal effects on offspring growth indicate post-weaning juvenile dependence in chimpanzees (Pan troglodytes verus). Frontiers in Zoology 17:1. doi:10.1186/s12983-019-0343-8

Sapolsky RM, Romero LM, Munck AU. 2000. How do glucocorticoids influence stress responses? Integrating permissive, suppressive, stimulatory, and preparative actions. Endocr Rev 21:55-89. doi:10.1210/edrv.21.1.0389

Saridjan NS, Huizink AC, Koetsier JA, Jaddoe VW, Mackenbach JP, Hofman A, Kirschbaum C, Verhulst FC, Tiemeier H. 2010. Do social disadvantage and early family adversity affect the diurnal cortisol rhythm in infants? The Generation R Study. Hormones and Behavior 57:247-254. doi:10.1016/j.yhbeh.2009.12.001

Schoenemann KL, Bonier F. 2018. Repeatability of glucocorticoid hormones in vertebrates: a meta-analysis. PeerJ 6:e4398. doi:10.7717/peerj.4398

Schoenle LA, Zimmer C, Miller ET, Vitousek MN. 2021. Does variation in glucocorticoid concentrations predict fitness? A phylogenetic meta-analysis. General and Comparative Endocrinology 300:113611. doi:10.1016/j.ygcen.2020.113611

Selye H. 1976. Stress in Health and Disease. London: Butterworth's.

Sephton SE, Sapolsky RM, Kraemer HC, Spiegel D. 2000. Diurnal Cortisol Rhythm as a Predictor of Breast Cancer Survival. J Natl Cancer Inst 92:994-1000. doi:10.1093/jnci/92.12.994

Shannon C, Champoux M, Suomi SJ. 1998. Rearing condition and plasma cortisol in rhesus monkey infants. American Journal of Primatology 46:311-321. doi:10.1002/(SICI)1098-2345(1998)46:4<311::AID-AJP3>3.0.CO;2-L

Smith R, Thomson M. 1991. 10 Neuroendocrinology of the hypothalamo-pituitaryadrenal axis in pregnancy and the puerperium. Baillière's Clinical Endocrinology and Metabolism 5:167-186. doi:10.1016/S0950-351X(05)80102-8

Smith SM, Vale WW. 2006. The role of the hypothalamic-pituitary-adrenal axis in neuroendocrine responses to stress. Dialogues Clin Neurosci 8:383-395.

Sonnweber R, Araya-Ajoy YG, Behringer V, Deschner T, Tkaczynski P, Fedurek P, Preis A, Samuni L, Zommers Z, Gomes C, Zuberbühler K, Wittig RM, Crockford C. 2018. Circadian Rhythms of Urinary Cortisol Levels Vary Between Individuals in Wild Male Chimpanzees: A Reaction Norm Approach. Front Ecol Evol 6. doi:10.3389/fevo.2018.00085

Sparkman AM, Bronikowski AM, Williams S, Parsai S, Manhart W, Palacios MG. 2014. Physiological indices of stress in wild and captive garter snakes: correlations, 
repeatability, and ecological variation. Comp Biochem Physiol, Part A Mol Integr Physiol 174:11-17. doi:10.1016/j.cbpa.2014.03.023

Stanton MA, Lonsdorf EV, Murray CM, Pusey AE. 2020. Consequences of maternal loss before and after weaning in male and female wild chimpanzees. Behav Ecol Sociobiol 74:22. doi:10.1007/s00265-020-2804-7

Steptoe A, van Jaarsveld CHM, Semmler C, Plomin R, Wardle J. 2009. Heritability of daytime cortisol levels and cortisol reactivity in children. Psychoneuroendocrinology 34:273280. doi:10.1016/j.psyneuen.2008.09.006

Stolwijk AM, Straatman H, Zielhuis GA. 1999. Studying seasonality by using sine and cosine functions in regression analysis. J Epidemiol Community Health 53:235-238.

Taff CC, Schoenle LA, Vitousek MN. 2018. The repeatability of glucocorticoids: A review and meta-analysis. General and Comparative Endocrinology 260:136-145. doi:10.1016/j.ygcen.2018.01.011

Tkaczynski PJ, Behringer V, Ackermann CY, Fedurek P, Fruth B, Girard-Buttoz C, Hobaiter C, Lee SM, Löhrich T, Preis A, Samuni L, Zommers Z, Zuberbühler K, Deschner T, Wittig RM, Hohmann G, Crockford C. 2020a. Patterns of urinary cortisol levels during ontogeny appear population specific rather than species specific in wild chimpanzees and bonobos. Journal of Human Evolution 147:102869. doi:10.1016/j.jhevol.2020.102869

Tkaczynski PJ, Mielke A, Samuni L, Preis A, Wittig RM, Crockford C. 2020b. Long-term repeatability in social behaviour suggests stable social phenotypes in wild chimpanzees. Royal Society Open Science 7:200454. doi:10.1098/rsos.200454

Tkaczynski PJ, Ross C, Lehmann J, Mouna M, Majolo B, MacLarnon A. 2019. Repeatable glucocorticoid expression is associated with behavioural syndromes in males but not females in a wild primate. Royal Society Open Science 6:190256. doi:10.1098/rsos.190256

Tsigos C, Chrousos GP. 2002. Hypothalamic-pituitary-adrenal axis, neuroendocrine factors and stress. J Psychosom Res 53:865-871.

Vehtari A, Gabry J, Mans M, Yao Y, Gelman A. 2019. loo: Efficient leave-one-out crossvalidation and WAIC for Bayesian models.

Vehtari A, Gelman A, Gabry J. 2017. Practical Bayesian model evaluation using leave-oneout cross-validation and WAIC. Stat Comput 27:1413-1432. doi:10.1007/s11222016-9696-4

Vehtari A, Simpson D, Gelman A, Yao Y, Gabry J. 2021. Pareto Smoothed Importance Sampling. arXiv:150702646 [stat].

Weitzman ED, Fukushima D, Nogeire C, Roffwarg H, Gallagher TF, Hellman L. 1971. Twentyfour Hour Pattern of the Episodic Secretion of Cortisol in Normal Subjects. None 33:14-22. doi:10.1210/jcem-33-1-14

Wessling EG, Deschner T, Mundry R, Pruetz JD, Wittig RM, Kühl HS. 2018a. Seasonal Variation in Physiology Challenges the Notion of Chimpanzees (Pan troglodytes verus) as a Forest-Adapted Species. Front Ecol Evol 6. doi:10.3389/fevo.2018.00060

Wessling EG, Kühl HS, Mundry R, Deschner T, Pruetz JD. 2018b. The costs of living at the edge: Seasonal stress in wild savanna-dwelling chimpanzees. Journal of Human Evolution 121:1-11. doi:10.1016/j.jhevol.2018.03.001 
983 Wilson AJ, Réale D, Clements MN, Morrissey MM, Postma E, Walling CA, Kruuk LEB, Nussey

984 DH. 2010. An ecologist's guide to the animal model. Journal of Animal Ecology

985

79:13-26. doi:10.1111/j.1365-2656.2009.01639.x

986

Wittig RM, Boesch C. 2019. Observation Protocol and Long-Term Data Collection in Taï In:

987 Boesch C, Wittig RM, Crockford C, Vigilant L, Deschner T, Leendertz F, editors. The

988 Chimpanzees of the Taï Forest: 40 Years of Research. Cambridge University Press. Female Chimpanzees of the Taï National Park. International Journal of Primatology 24:847-867. doi:10.1023/A:1024632923180

Wittig RM, Crockford C, Weltring A, Deschner T, Zuberbühler K. 2015. Single Aggressive Interactions Increase Urinary Glucocorticoid Levels in Wild Male Chimpanzees. PLOS ONE 10:e0118695. doi:10.1371/journal.pone.0118695

Wittig RM, Crockford C, Weltring A, Langergraber KE, Deschner T, Zuberbühler K. 2016. Social support reduces stress hormone levels in wild chimpanzees across stressful events and everyday affiliations. Nature Communications 7:13361. doi:10.1038/ncomms13361

Zhang TY, Labonté B, Wen XL, Turecki G, Meaney MJ. 2013. Epigenetic Mechanisms for the Early Environmental Regulation of Hippocampal Glucocorticoid Receptor Gene Expression in Rodents and Humans. Neuropsychopharmacology 38:111-123. doi:10.1038/npp.2012.149

Zilioli S, Slatcher RB, Chi P, Li X, Zhao J, Zhao G. 2016. Childhood Adversity, Self-Esteem, and Diurnal Cortisol Profiles Across the Life Span. Psychol Sci 27:1249-1265. doi:10.1177/0956797616658287

Zipple MN, Archie EA, Tung J, Altmann J, Alberts SC. 2019. Intergenerational effects of early adversity on survival in wild baboons. eLife 8:e47433. doi:10.7554/eLife.47433 